\title{
Netflix Bigdata Analytics- The Emergence of Data Driven Recommendation
}

\author{
Srivatsa Maddodi ${ }^{1,2}$ and Krishna Prasad. K. ${ }^{3}$ \\ ${ }^{1}$ Research Scholar, College of Computer and Information Science, Srinivas University, \\ Mangaluru, Karnataka, India \\ ${ }^{2}$ Data Engineer Specialist, Analytics and Data Management, DXC Technology, Bengaluru, \\ Karnataka, India \\ ${ }^{3}$ College of Computer and Information Science, Srinivas University, Mangaluru, Karnataka, \\ India \\ Email: srivatsa.maddodi@gmail.com
}

Type of the Paper: Explorative Research.

Type of Review: Peer Reviewed.

Indexed In: OpenAIRE.

DOI: http://doi.org/10.5281/zenodo.3510316.

Google Scholar Citation: $\underline{\text { IJCSBE }}$

\section{How to Cite this Paper:}

Srivatsa Maddodi, \& Krishna Prasad, K. (2019). Netflix Bigdata Analytics- The Emergence of Data Driven Recommendation. International Journal of Case Studies in Business, IT, and Education (IJCSBE), 3(2), 41-51.

DOI: http://doi.org/10.5281/zenodo.3510316.

International Journal of Case Studies in Business, IT and Education (IJCSBE)

A Refereed International Journal of Srinivas University, India.

IFSIJ Journal Impact Factor for 2019-20 = 4.252

(C) With Authors.

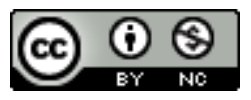

This work is licensed under a Creative Commons Attribution-Non Commercial 4.0 International License subject to proper citation to the publication source of the work.

Disclaimer: The scholarly papers as reviewed and published by the Srinivas Publications (S.P.), India are the views and opinions of their respective authors and are not the views or opinions of the S.P. The S.P. disclaims of any harm or loss caused due to the published content to any party. 


\title{
Netflix Bigdata Analytics- The Emergence of Data Driven Recommendation
}

\author{
Srivatsa Maddodi ${ }^{1,2}$ and Krishna Prasad. K. ${ }^{3}$ \\ ${ }^{1}$ Research Scholar, College of Computer and Information Science, Srinivas University, \\ Mangaluru, Karnataka, India \\ ${ }^{2}$ Data Engineer Specialist, Analytics and Data Management, DXC Technology, Bengaluru, \\ Karnataka, India \\ ${ }^{3}$ College of Computer and Information Science, Srinivas University, Mangaluru, Karnataka, \\ India \\ Email: srivatsa.maddodi@gmail.com
}

\begin{abstract}
Netflix is one of the largest online streaming media providers. It began its operations in 1997.Founded by two tech entrepreneur Reed Hastings and Marc Randolph. The Company's head office is in Los Gatos, California. Netflix's initially started selling DVDs or provide them on a rental basis. Over the period with growth of internet users and the decline of DVD sales and rental services, it changed its business model to video on demand. From 2012 onwards, it started producing its original TV-series and movies. Netflix uses bigdata analytics to understand its customers base better. By using these data, they provide better service or product to the customer. Netflix collects huge amounts of data from a vast variety of subscriber base. It collects data such as the location of a user; content watched by the user, user interests, the data searched by the user, and the time at which user watched. Based on these parameters its algorithm gives a personalized recommendation based on the user interest. Netflix has constantly focused on changing business needs they have moved their business model from DVD rental to video on demand and currently producing original shows. In this paper we analyze various business strategies of Netflix. This paper also analyzes how Netflix with the help of bigdata analytics focused on improving the subscriber's experience and how it helped to be more customer-centric and increased its user base. Based on the SWOT and PESTLE analysis we have provided some suggestion that can be incorporated by Netflix as business strategy.
\end{abstract}

Keywords: Netflix, Bigdata, Data analytics, Customer experience, Video on demand, Streaming.

\section{INTRODUCTION :}

Netflix, Inc was founded by two tech entrepreneur Reed Hastings and Marc Randolph. It began its operations in the year of 1997. The Company's head office is in Los Gatos, California. Netflix's Main business is subscription-based online streaming services of TV Shows, Originals, Movies, etc. Being the largest media service provider, it has over 148 Million members operated across 190 countries except for China, Iran, North Korea, Crimea, and Syria [1]. During the initial days Netflix suffered huge loss but with the raise of internet users and Netflix changed its business model from traditional DVD rental and sales to the introduction of online video streaming in 2007. Netflix was able to reduce the loss. To make this possible Netflix needed to change their business strategy. Along with the streaming on movies, TV-Shows from another studios Netflix is also producing its own movies and TV-Shows. From 2010 Netflix started its expansion worldwide starting from Canada in 2010 than in Latin American countries in the year 2011 followed by United Kingdom and other European Countries like Denmark, Netherlands, Norway etc. from 2012 till 2015.In the year 2012 Netflix has split its business of DVD rental service as a Separate division from online streaming division. Till 2017 DVD rental division has around 3.3 million customers and Netflix has plans to 
keep this service for few more years. The biggest challenge currently faced by Netflix are Maintaining the existing subscribers and increasing the new subscriber count, increase in competition by other streaming providers like Hulu, Disney, Warner Media, Amazon, the rise of the cost to produce the original content. To overcome these challenges Netflix uses Bigdata Analytics. Netflix has heavily invested in research on bigdata analytics it spends over $\$ 1$ billion for it. As of today, they have a separate division called Netflix Research that mainly concentrates on data analytics areas such as customer experience, recommendations, machine learning, etc. They are heavily invested in Data Sciences and Data Analytics for their recommendation systems. These recommendation systems understand the users and provide recommendation accordingly.

This paper has total 9 sections. Section 1 provides brief introduction about Netflix. Section 2 explains about the objectives of this case study. Section 3 describes the methodology used in this case study. Section 4 describes the Evolution of business model at Netflix and compares its business model with its rival Blockbuster Inc. Section 5 describes how Bigdata Analytics is used in Netflix in their recommendation system and to provide better customer experience. Section 6 explains SWOT and PESTLE analysis of Netflix. Section 7 provides the findings of this study. Section 8 provides recommendations and suggestion based on SWOT and PESTLE analysis and finally this paper concludes with Section 9 Conclusion.

\section{OBJECTIVES :}

Below are the objectives of study

1. History of Netflix.

2. To understand about the evolution of business model at Netflix.

3. To understand about the strategies of Netflix and how new strategies are used to overcome challenges faced by competition.

4. Overview of recommendation system.

5. To understand how Bigdata analytics is used by Netflix to improve customer satisfaction.

6. Use of SWOT and PESTLE analysis for recommendation of Netflix future strategies.

\section{RESEARCH METHODOLOGY :}

The primary goal of this case study is to understand how Netflix uses Bigdata analytics in their recommendation system. The Study is conducted based on the multiple sources available over world wide web. The main sources are Netflix Inc website, Blockbuster Inc website, Bigdata analytics, recommendation system blogs and multiple conference/journal articles related to bigdata and recommendation system. Google scholar is primarily used as search engine to retrieve the literature relevant to the case study. The main reason for choosing google scholar is as it is free to use, and it has a very vast catalogue of academic articles. It provides multiple features like export of citation individually and citation tracking.

\section{NETFLIX vs. BLOCKBUSTER-EVOLUTION OF BUISNESS MODEL :}

Netflix was the main competitor for Blockbuster Inc which is into the business of DVD sales and rental through their physical stores. Blockbuster started in year 1985 was an undisputed leader in the entertainment service business with more than 2800 physical stores. Blockbuster was selling and renting DVD through its stores across worldwide [2]. Netflix came with the unique idea of DVD sales and rental business without physical store. Using the Netflix website from the catalogue one must choose the movies/TV-shows what they want, and Netflix used to send the DVD through postal service. During the early days Netflix started offering DVD on rental basis. Netflix realized that it is spending more per customer than what it was earning through rent of DVD. So, it changed its business model to Subscription method where it was offering DVD rental to its customers who subscribed for a fixed fee. Unlike its rival Blockbuster Netflix was not charging any late fee from the return of the DVD. Since inception Netflix was not profitable and was losing money one of its founder Reed Hastings in the year 2000 approached Blockbuster CEO John Antioco with the offer of Netflix being taken over by Blockbuster for $\$ 50$ Million. His idea was Netflix team would manage Blockbuster's Online brand and Blockbuster needs to promote Netflix in their stores however this deal was rejected by Blockbuster's team [3]. The major challenge the Netflix faced is a very high 
demand for new and super hit movies, sometimes this resulted in customer being not happy due to movies not been available. To address this Netflix came up with the idea of Netflix recommendation system this resulted in the decrease of $20 \%$ for the demand of new releases compared to the traditional DVD rental services like Blockbuster. Both Blockbuster and Netflix competed against each other for the same market, but their business model was different. Blockbuster business model was based on idea that most movie rentals happen based on the impulse decision of user who may want to watch the movie immediately these are new releases or hit movies, so their stores mainly concentrated on that aspect. Netflix business model was based on considering movies as regular entertainment. Instead of pickup like Blockbuster Netflix delivered the movies through postal service. Customer ability to keep the movies for longer time and convenience to return through postal service attracted more customers to Netflix. Blockbuster was very late to adapt changes and by the time when they realized the threat from Netflix and planned to launch similar model as of Netflix in the year 2004. But due to change in management the idea did not materialize, and they continued their older business model. Finally, the company went bankrupt and closed its operations in 2013.

\section{BIGDATA ANALYTICS AT NETFLIX :}

Netflix was one of the early adapters of Bigdata Analytics in the year 2006 Netflix came up with a challenge that would award $\$ 1$ Million to anyone who would improve their existing recommendation system called Cinematch by $10 \%$ [4]. The challenge was to develop and algorithm to predict the subscriber movie preference based on the older data. Netflix provided the dataset which contains about 100 million ratings provided by 480 thousand users for 17 thousand movies, Ratings were in the form like user, movie name, date of rating and rating provided by the user. The competition was carried over years and in the year 2008 the prize was awarded to BellKor's Pragmatic Chaos team which consisted of Mathematician, data scientist and engineers from different counties and from different industries and research institute including AT\&T, Yahoo \& Commendo Research \& Consulting $\mathrm{GmbH}$ [5].This competition was a grand success many teams that participated in this competition has provided similar solution to other companies like ecommerce. However, the second competition which was announced by Netflix in the year 2010 had to be cancelled due to privacy issue lawsuit against the Netflix for the dataset that has been used in the competition.

Netflix uses Data Science and Bigdata Analytics in their recommendation systems. In late 1990's, the term recommender system was introduced for the first time in literature of information system [6]. The interest in recommendation system remains as it is widely applicable to solve the practical problems of many companies. Many companies like amazon, Microsoft etc. have a commercial recommendation system [7-8].

\subsection{NETFLIX RECOMMENDATION SYSTEM:}

It recommends the subscribers various choices based on their interests. Recommendation systems use Machine learning. It takes inputs from user and recommends appropriately. In Netflix recommendation system collects user data such as the location of a user; content watched by the user, user interests, the data searched by the user, and the time at which user watched. Based on these parameters its algorithm gives a personalized recommendation based on the subscriber's interest. Mostly recommendation systems take user profile as an important parameter. Subscriber profile consists of different types of information such as interest of a subscriber, history of subscriber search query, interaction with system etc. Whenever a new subscriber account is created, or a new profile is added to existing account Netflix will ask the subscriber to choose few genre or titles which can be used as initial parameters for recommendation system. If the subscriber skips this step, then Netflix will populate the user homepage with the popular set of contents. Once the user starts watching the content then this will super cede any initial preferences provided by subscriber. As the subscriber continues to watch. The content which was watched previously will be used to provide the recommendation further [9-10].

There are two types of recommendation system [11]

1. Content-based

2. Collaborative filtering

Content-based filtering: This type of recommendation system is based on the history of the subscriber. The Subscriber will watch a content or movies of a kind like action or comedy again if he 
has viewed a similar content in past as described in Fig.1. This type of recommendation system takes the customer information [12]. Initially when any subscriber has just joined the service it asks the subscriber to provide the information like which genre he likes and some other information. Some of the data that is collected by the subscribers are as below It asks the user to rate the content.

- User Search data.

- Rank the content from least favorite to most favorite.

- Choose the better of two items.

- Ask the user to create what he likes and what he dislikes.

- Analyzing the user search data.

- Tracking the users viewing history.

Collaborative filtering: This kind of recommendation system is based on similar profiles of users [13]. To create a subscriber profile the recommendation system mainly focuses on the below two information.

- Subscriber preferences.

- History of subscriber

For instance, if a subscriber A watches crime, action, horror movies and subscriber B watches crime, action, comedy movies then subscriber A will like to watch comedy movies and subscriber B will like to watch horror movies. Please refer Fig.1.

\section{COLLABORATIVE FILTERING}

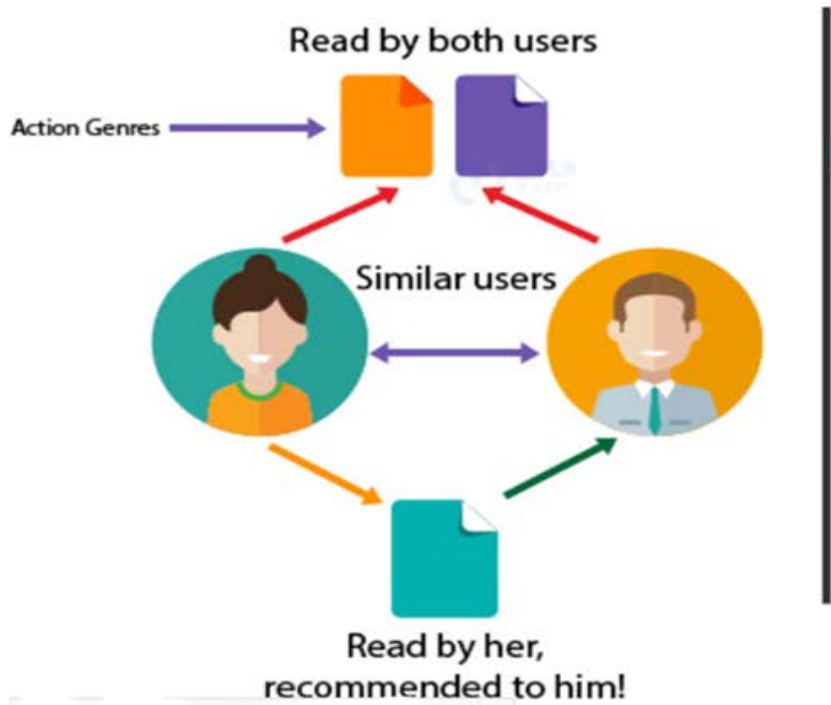

\section{CONTENT-BASED FILTERING}

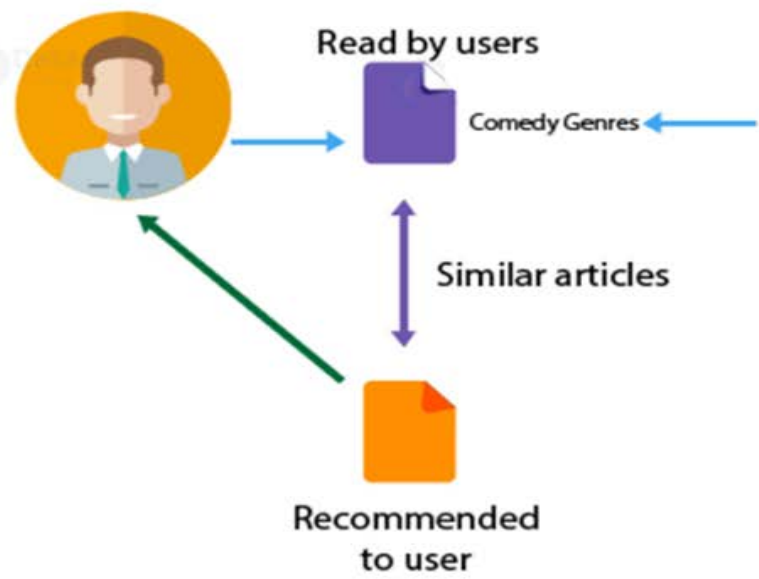

Fig.1: Recommendation Technique

Hybrid Recommendation System: This type of recommendation system is the combination of content and collaborative recommendation system. Netflix uses hybrid approach of the recommendation system. In this recommendation system a recommendation is made by combining the viewing habits of the subscriber and searching habits of the subscriber with previous history of the subscriber. Below are few of the hybrid recommendation techniques

Weighted: In this type of hybrid technique two or more recommendation system will provide a recommendation to user based on the user preference and finally the scores of different recommendation systems are combined to achieve a high accuracy.

Feature Combination: In this type of hybrid technique the output of one or more commendation system is provided as input to the final recommendation system.

Cascade: This type of hybrid recommendation system is staged recommendation process and is based on priority. 
Switching: In this type of hybrid approach based on some criteria switching happens between the recommendation systems.

Feature Augmentation: In this type of hybrid approach the output of one recommendation system is provided as input to other recommendation system.

Meta-level: This type of hybrid recommendation system is order sensitive.

Mixed: This type of hybrid recommendation system is the simplest one. In this different kind of recommendation system are combined to provide the recommendation.

\section{Limitation of Recommendation System:}

- Cold-Start: For any new subscriber there is not enough data available to make recommendation at beginning.

- Scalability: As there are vast number of users and contents. A huge amount of computational power is necessary to provide accurate recommendation with shortest time possible.

- Data Sparsity: As the database is huge the most active users might have rated only a few of content.

- Accuracy: It is one of the major limitations as it deals with the ability of recommendation system to predict what a user wants more accurately.

- Diversity: This is helpful in avoiding bias. There should be a diverse set of recommendation to be available.

\subsection{PREDECTING VIEWING HABITS OF SUBSCRIBER:}

To provide personalized recommendations to its subscribers Netflix collects huge amount of data from its user base. Below are some of the things which Netflix tracks

- When a user stops a content.

- When a user fast forwards a content.

- When a user pauses a content.

- Time during which the user watch.

- Location of the user.

- What content the user watch.

- On what device does he watch (TV, Smartphone etc.)

- Browsing behavior of user.

- Searching habit of user.

- Reviews and ratings given by user.

Based on these data Netflix gives personalized recommendations.

\subsection{FINDING THE NEXT HIT TV-SERIES: A STUDYONHOUSEOF CARDS:}

Netflix has entered production and distribution of originals. It started producing its original TVShows. The strategy used by Netflix is driven by bigdata. Netflix won the bid to produce House of Cards against various other competitors like HBO, AMC. The very interesting fact was without seeing a single episode of the show Netflix committed \$100 Million for the show of 2 seasons consisting of 26 episodes. This decision was driven by bigdata analytics. By analyzing the past viewer data Netflix was able to determine that users of original House of Cards which aired on United Kingdom in 1990's were interested to watch movies directed by David Fincher and actor Kevin Spacey. Netflix was so confident that the show what they would produce would turn out to be a super hit based on the bigdata analytics. Netflix has around $80 \%$ success rate for original content compared to other networks whose success rate is by far less then Netflix. The production or original content is decided by running Bigdata analytics and other data mining algorithms to determine the size of the audience who would watch these original contents.

\subsection{NETFLIX PERSONALIZE CUSTOMER EXPERIENCE:}

Netflix uses A/B test to personalize user experience. Whatever the it is shown on the platform (eg: images) is driven by data collected by A/B test. Each test present two different versions for subscriber and observe how the subscriber react to these. Netflix uses landing cards. Landing cards are images or video teasers that can be seen in the homepage of the subscriber. Landing cards is helpful in attracting the subscriber to watch the content. Users are more likely to watch the content if the images are attractive to them [14]. 


\section{ANALYSIS :}

Both SWOT and PESTLE analysis are performed as per the guidelines mentioned in Company analysis case study [15-21]

Company Background [22]

Company: Netflix Inc

CEO: Reed Hastings

Year founded: 1997

Founders: Reed Hastings and Marc Randolph

Headquarter: Los Gatos, USA

Industry: Cable/Satellite TV

Number of Employees (2018): 5,500

Public or Private: Public

Ticker Symbol: NFLX

Market Cap (Feb 2019): \$155.81 Billion

Annual Revenue (2018): \$15.79 Billion

Profit |Net income (2018): \$1.21 Billion

Products \& Services: Video on demand, online streaming

Competitors: Hulu | Disney+ | HBO| Warner Media | Amazon |

SWOT Analysis: SWOT analysis can be used by organization to identify internal factors that is of strategic importance like Strength and Weakness of an organization and External factors like Opportunities and Threats.

SWOT analysis helps the organization to develop four types of strategies as below

SO-Strength-opportunities Strategy.

WO-Weakness-opportunities Strategy.

ST-Strength-Threat Strategy.

WT-Weakness-Threat Strategy.

Strengths:

- Established Brand Name.

- Reliable distribution network.

- Global Customer Base: Netflix is serving over 190 countries worldwide.

- Good performance in new markets.

- Successful track record.

- Successful market strategies.

- Technology: Netflix is ready to embrace changes rapidly it is one of the early adapters of bigdata analytics and data science.

- Product innovation.

- Original Content: Netflix is in production of original content and the quality of the content which Netflix produces are liked by many viewers.

\section{Weakness:}

- Huge Debt: The production of original content involves huge costs this results in debts.

- Limited Copyrights: For many of shows or movies Netflix has taken rights from other studios. It is becoming difficult to manage the content library as the rights taken from other studios expire and the content will be taken off from Netflix.

- More investment in newer technologies.

- No success outside core business.

\section{Opportunities:}

- Expansion into other countries including China.

- Partnership in Europe to meet European laws.

- Alliances: It can partner with various service providers to provide bundle packages at discounted price.

- Potential to earn revenue by other means like advertisements.

- Attracting New customer base with the use of data analytics. 


\section{Threats:}

- Increased Competition: Other Providers like Hulu, HBO, Amazon, Disney and Warner Media are entered or entering the online streaming service.

- Piracy: It is the biggest threat many users download the content by illegal means.

- Increasing the Subscription price lead to subscribers switch to other providers.

- Sharing of Single Subscription between multiple users.

- Change of subscriber behavior

- Different countries liability laws.

PESTLE Analysis: PESTLE analysis is used to analyze the macro environment of any organization.

PESTLE stands for

P-Political

E-Economical

S-Socio-Cultural

T-Technological

L-Legal

E-Environmental

PESTLE analysis provides a detail analysis of macro environment of organization along with its operational challenges

Political:

- Due to European regulations Netflix belonged to same category as television distributors. Netflix needs to follow the European rule that $30 \%$ of the content needs to be European.

- Due to restrictions of US on some countries like Crimea, North Korea Netflix cannot expand to those countries.

- Due to permission issue by Chinese government Netflix could not expand its business to china.

- Existing petition in US by AT\&T in Federal Communication Commission to limit online streaming platforms like Netflix.

- Censorship: different countries has different laws regarding censorship. US content may not be suitable for many countries where it needs to be highly censored.

- Mandatory Employee benefits.

Economical:

- Change of exchange rates impacts the revenue of Netflix.

- Competitive pricing.

- The price of Netflix in US is much lower than traditional service providers.

- Tax laws in different states of US.

- Inflation and Interest rates.

- Skill level of workforce.

- Cost per Employee.

Socio-Cultural

- Many Customers are moving to watch content through their smartphone.

- Netflix is known for charity work like providing scholarships.

- Demographics and skill level of countries population.

\section{Technological:}

- Recent technological advancement and impact on product offerings.

- Improving quality of streaming with less data consumption to support $4 \mathrm{~K}$ content efficiently.

- A new software called 'Hermes' is developed by Netflix Research which automatically grades a translation. With the use of this Netflix will be able to serve the faster and good quality translation of shows to different countries.

Legal:

- Due to copyright laws Netflix has introduced blockers that will block the users accessing the contents from other countries this will affect the user base.

- They need to handle the video piracy affectively. 
- Employment law.

- Copyright and Intellectual property.

- Consumer protection law.

\section{Environmental:}

- Netflix needs to work more towards using of renewable energy and reduce the carbon footprint of its data centers.

- Recycling and waste management.

- Use of ecological products.

\section{FINDINGS OF THE STUDY :}

- Netflix is one of the early adapters in bigdata analytics.

- Use of bigdata analytics has resulted in customer satisfaction.

- Data analytics has helped Netflix in production of original content.

- Data analytics has helped Netflix to be leader of streaming market.

\section{SUGGESTION AND RECOMMENDATIONS :}

Based on the SWOT and PESTLE analysis below are few recommendations

- Netflix to continue its use on Data analytics and Data Science to improve the customer experience.

- It is recommended to reduce the subscription cost as similar as its competitor for developing countries like India.

- Use of limited Advertisements to compensate loss of revenue due to lower subscription prices.

- Explore other territories for expansion.

- Produce more original content region specific.

- Tie Ups with different production studios to increase the content library.

- Use of advanced authentication techniques like finger print or facial recognition [23-26] or Multi factor authentication [27-28] for subscriber authentication.

\section{CONCLUSION :}

In this paper we have discussed regarding business model of Netflix comparing it with the business model of Blockbuster Inc and how Netflix was able to beat its competitor to become leading online streaming service provider. We discussed about the Netflix prize competition and how the winning team algorithm made the existing algorithm of Netflix more accurate. We have also discussed about the different kinds of recommendation system like content based and collaborative filtering recommendation system and use of Hybrid recommendation technique by Netflix.Also, we have analyzed how with Bigdata Analytics is used for its recommendation system to improve the customer experience. We have also discussed how Netflix with the help of bigdata analytics can predict the viewing habits of subscriber and how it helped in producing the original content which would be a huge success.Finally Based on the SWOT and PESTLE analysis we have provided few recommendations to Netflix to improve their business strategy.

\section{REFERENCES :}

[1] Netflix.In Wikipedia. Retrieved 09/08/2019, from https://en.wikipedia.org/wiki/Netflix

[2] Blockbuster.In Wikipedia. 09/08/2019, fromhttps://en.wikipedia.org/wiki/Blockbuster_LLC

[3] Davis, Todd and Higgins, John (2013), A Blockbuster Failure: How an Outdated Business Model Destroyed a Giant. Chapter 11 Bankruptcy Case Studies. from

http://trace.tennessee.edu/utk studlawbankruptcy/11

[4] R.M. Bell and Y. Koren (2007). Lessons from the Netflix prize challenge.ACM SIGKDD Explorations Newsletter,9(2):75-79. 
[5] Dataflair Team (2019) Data Science at Netflix- A Must Read Case Study for Aspiring Data Scientists [Blog post]. Retrieved August 09,2019, from https://data-flair.training/blogs/data-scienceat-netflix/

[6] Resnick P, Varian H (1997). Recommender systems. Commun.ACM30(3):56-58

[7] Linden G, Smith B, York J (2003). Amazon.com Recommendations: Item-to-Item Collaborative Filtering. Published by the IEEE Computer Society, IEEE InternetComput. 7(1):76-80.

[8] ShaniG, Gunawardana A (2011). Evaluating Recommendation Systems. Springerpp.257-298

[9] Netflix. How Netflix Recommendation System Works.Retrieved 09/08/2019, from https://help.netflix.com/en/node/100639

[10]Carlos A. Gomez-Uribe and Neil Hunt. (2015). The Netflix recommender system: Algorithms, business value, and innovation. ACM Trans. Manage. Inf., 6(4), 1-19. DOI: http://dx.doi.org/10.1145/2843948

[11] Adomavicius G, Tuzhilin A (2005). Toward the Next Generation of Recommender Systems: A Survey of the State-of-the-Art and Possible Extensions. IEEETrans. Knowl. Data Eng. 17(6):734749 .

[12] Pazzani M.J., Billsus D. (2007) Content-Based Recommendation Systems. In: Brusilovsky P., Kobsa A., Nejdl W. (eds) The Adaptive Web. Lecture Notes in Computer Science, vol 4321. Springer, Berlin, Heidelberg

[13] Balabanovic, M., Shoham Y. (1997). FAB: Content-based, Collaborative Recommendation. Com-munications of the Association for Computing Machinery 40(3), 66-72.

[14] Astha Khandelwal. Deliver Personalized Recommendations The Amazon-\&-Netflix Way! [Blog Post]. Retrieved 15/08/2019, fromhttps://vwo.com/blog/deliver-personalized-recommendations-theamazon-netflix-way.

[15] Aithal, P. S. (2017). Industry Analysis - The First Step in Business Management Scholarly Research. International Journal of Case Studies in Business, IT and Education (IJCSBE), 2(1), 1-13. DOI: http://dx.doi.org/10.5281/zenodo.810347.

[16] Aithal, P. S. and Suresh Kumar, P. M. (2015). Applying SWOC Analysis to an Institution of Higher Education. International Journal of Management, IT and Engineering (IJMIE), 5(7), 231-247. DOI: http://doi.org/10.5281/zenodo.163425.

[17] Aithal, P. S. (2017). An Effective Method of Developing Business Case Studies Based on Company Analysis. International Journal of Engineering Research and Modern Education (IJERME), 2(1), 16-27. DOI: http://dx.doi.org/10.5281/ZENODO.400579.

[18] Aithal, P. S., (2017). ABCD Analysis as Research Methodology in Company Case Studies. International Journal of Management, Technology, and Social Sciences (IJMTS), 2(2), 40-54. DOI: http://dx.doi.org/10.5281/zenodo.891621.

[19] Aithal P. S. (2017). Impact of Domestic, Foreign, and Global Environments on International Business Decisions of Multinational Firms: A Systematic Study. International Journal of Management, Technology, and Social Sciences (IJMTS), 2(2), 57-73. DOI:http://dx.doi.org/10.5281/zenodo.1067103.

[20] Aithal, P. S., (2017). Company Analysis - The Beginning Step for Scholarly Research. International Journal of Case Studies in Business, IT and Education (IJCSBE), 1(1), 1-18. DOI: http://dx.doi.org/10.5281/zenodo.573769.

[21] Aithal, P. S. and Suresh Kumar, P. M. (2015). Applying SWOC Analysis to an Institution of Higher Education. International Journal of Management, IT and Engineering (IJMIE), 5(7), 231-247. DOI: http://doi.org/10.5281/zenodo.163425.

[22] Netflix. Netflix Annual SEC Report (2019). Retrieved 15/08/2019, from 
https://www.netflixinvestor.com/financials/sec-filings/default.aspx

[23] Krishna Prasad, K., Aithal, P. S. (2017). A Conceptual Study on Image Enhancement Techniques for Fingerprint Images. International Journal of Applied Engineering and Management Letters (IJAEML), 1(1), 63-72. DOI:http://dx.doi.org/10.5281/zenodo.831678.

[24] Krishna Prasad, K. and Aithal, P. S. (2017). A Conceptual Study on User Identification and Verification Process Using Face Recognition Techniques. International Journal of Applied Engineering and Management Letters (IJAEML), (ISSN Applied), 1(1), 6-17.

DOI:http://doi.org/10.5281/zenodo.810343.

[25] Krishna Prasad, K. \&Aithal, P.S. (2017). Fingerprint Image Segmentation: A Review of State of the Art Techniques. International Journal of Management, Technology, and Social Sciences (IJMTS), 2(2), 28-39. DOI: http://dx.doi.org/10.5281/zenodo.848191.

[26] Krishna Prasad, K. \&Aithal, P.S. (2017). A Study on Fingerprint Hash Code Generation using Euclidean Distance for Identifying a User. International Journal of Management, Technology, and Social Sciences (IJMTS), 2(2), 116-126. DOI:http://doi.org/10.5281/zenodo.1133545.

[27] Krishna Prasad, K. \&Aithal, P.S. (2018). A Comparative Study on Fingerprint Hash Code, OTP, and Password based Multifactor Authentication Model with an Ideal System and Existing Systems. International Journal of Applied and Advanced Scientific Research, 3(1), 18-32. DOI: http://doi.org/10.5281/zenodo.1149587.

[28] Krishna Prasad, K. \&Aithal, P. S. (2018). A Study on Multifactor Authentication Model UsingFingerprint Hash Code, Password and OTP. International Journal of Advanced Trends in Engineering and Technology, 3(1), 1-11. DOI: http://doi.org/10.5281/zenodo.1135255. 